view, the database search for IAP-derived targets in introns showed that most occurred in the antisense orientation. It is not clear why the frequencies of sense and antisense IAP insertions are different in two strains of mouse living in a similar geographic area. Notably, Nxf1 ${ }^{\mathrm{CAST} / \mathrm{Ei}}$ cannot alter transcription from the LTR promoter; that is, it does not affect IAP mutations related to transcriptional initiation. This observation suggests that Nxf1 is probably not the only retroviral suppressor acting in the host cell.
Suppression of retrovirus insertional mutations is certainly a new defensive strategy against mobile DNA in the genome. The finding will have an impact on our current knowledge of retrovirus control and, as the authors point out, it will be extremely valuable for titrating mutations caused by retroviruses in vivo. One can also imagine that, in the near future, new forms of the Nxf1 factor could be helpful in a gene therapy approach using retrovirus vectors, where the risk of insertional mutagenesis is still present.
1. International Human Genome Sequencing Consortium. Nature 409, 860-921 (2001)

2. Goodier, J.L., Ostertag, E.M., Du, K. \& Kazazian, H.H. Jr. Genome Res. 11, 1677-1685 (2001).

3. Kuff, E.L. \& Lueders, K.K. Adv. Cancer Res. $\mathbf{5 1}$ 183-276 (1988).

4. Walsh, C.P., Chaillet, J.R. \& Bestor, T.H. Nat. Genet. 20, 116-117 (1998).

5. Zhao, X. et al. Proc. Natl. Acad. Sci. USA 100, 6777-6782 (2003).

6. Floyd, J.A. et al. Nat. Genet. 35, 221-228 (2003).

7. Hamilton, B.A. et al. Neuron 18, 711-722 (1997).

8. Johnson, K.R. et al. Hum. Mol. Genet. 8, 645-653 (1999).

9. Tabernero C. et al. J. Virol. 71, 95-101 (1997).

10. Grant, R.P., Hurt, E., Neuhaus, D. \& Stewart, M. Nat. Struct. Biol. 9, 247-251 (2002).

\title{
A molecular signature of behavior
}

This worker is returning to the hive laden with pollen, which makes her a forager in the world of Apis mellifera, the honey bee. What she is also carrying, unbeknownst to her, is a gene expression signature in her brain that differentiates her from her sibs left to look after the hive. This knowledge comes from a recent study by Charles Whitfield and colleagues (Science 320, 296-299; 2003) in which they profiled gene expression in the brains of bees whose job it is to bring home food and those who stay home to tend the hive.

During the first 2-3 weeks of adult life, honey bees are assigned various tasks in the hive, including nursing the young. The bees are then promoted to tasks outside the hive, such as foraging for nectar and pollen, which they carry out until the end of their lives some 5-7 weeks later. The timing of this transition is flexible according to the needs of the colony. When it occurs, it is associated with changes in brain structure and neurochemistry. The degree to which these changes are associated with gene expression changes has so far not been known.

Using a microarray with probes for 5,500 different genes, an initial comparison of the brains of nurse and forager bees showed expression differences for $39 \%$ of genes. This analysis, however, is confounded by the fact that nurses are younger than foragers and, therefore, expression differences may be associated with age rather than behavior. To dissociate age from behavior, the authors created colonies with only young bees. In these colonies, some of the younger bees became foragers earlier than usual and some remained nurses for much longer. Microarray analysis was

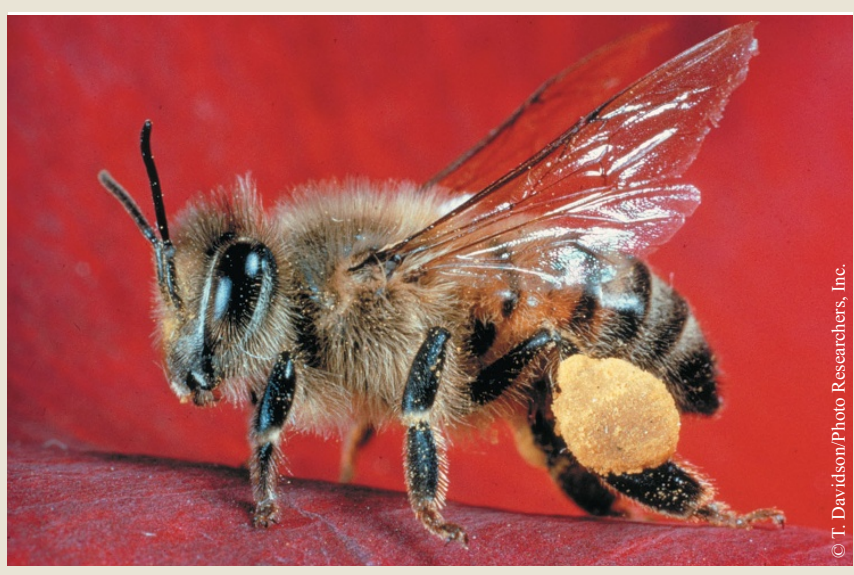

performed on the brains of these young foragers and old nurses. Class prediction analysis was then able to determine behavioral phenotype using a set of 50 genes.

The set of 50 genes encode proteins that could conceivably have a role in mediating changes in the brain and behavior. Examples include cell adhesion molecules, molecules involved in intracellular signaling and carbonic anhydrase, which is known to have a role in spatial learning and memory. As with other genetic signatures, however, determining whether these expression differences are a cause or an effect of behavioral change awaits further investigation.

David Gresham 